\title{
Acute carbon monoxide intoxication during pregnancy. One case report and review of the literature
}

\author{
J L Greingor, J M Tosi, S Ruhlmann, M Aussedat
}

Acute carbon monoxide (CO) poisoning during pregnancy is an uncommon event, but failing to recognise maternal $\mathrm{CO}$ intoxication can have a dramatic effect on the fetus. To limit the toxic effects of $\mathrm{CO}$, the use of hyperbaric oxygen is usually recommended. We report the case of one patient admitted for acute $\mathrm{CO}$ poisoning during pregnancy.

\section{Case report}

A 31 year old (gravida 4, para 3) at 21 weeks gestational age was exposed to $\mathrm{CO}$. $\mathrm{CO}$ was produced by a defective water heater. She did not lose consciousness and her vital signs were: regular pulse rate of 90 beats per minute, blood pressure of 100/80 $\mathrm{mm} \mathrm{Hg}$ and respirations of $201 / \mathrm{mn}$. Physical examination was unremarkable. She complained of dizziness and palpitation. She was promptly removed from the source of CO. The patient received $91 / \mathrm{mn}$ supplemental oxygen by face mask.

A level of $24.6 \%$ carboxyhaemoglobin was measured in the expired air. High flow oxygen therapy was started immediately. The patient was then treated with $100 \% \quad \mathrm{O}_{2}$ at 2.5 atmospheres absolute for 90 minutes. Treatment with hyperbaric oxygen was started in the 30 minutes after the end of exposure. Sonography confirmed the presence of fetal heart tone of $140 / \mathrm{mn}$.

She was discharged in good health one day after exposure. The patient delivered at term a healthy male infant weighing $3800 \mathrm{~g}$.

\section{Discussion}

CO intoxication is the most frequently reported poisoning in Western developed countries. In England and Wales acute CO poisoning was responsible for 877 deaths in $1996 .{ }^{1}$ In France and in the USA, CO is the leading cause of death by poisoning. ${ }^{23}$ Many situations result in the production of CO. Signs are variable and non-specific and may easily be confused with those of other disorders. This explains the difficulty of a diagnosis of acute $\mathrm{CO}$ intoxication. Hardy estimates that nearly one third of all cases may go undiagnosed. ${ }^{4}$

Breslau and Freund were responsible for the first published report of acute $\mathrm{CO}$ intoxication in pregnant women. Breslau reported the intoxication of two pregnant women admitted to a Zurich hospital after a gas explosion. ${ }^{5}$ One woman had an apparently normal child at delivery, but the other suffered a stillbirth: the death occurring one day after exposure. Freund reported a death in utero during the seventh month of gestation. ${ }^{6}$ The frequency of acute $\mathrm{CO}$ poisoning during pregnancy is difficult to estimate. In France, Elkharrat et al found that $4.6 \%$ of hospitalised victims of $\mathrm{CO}$ poisoning were pregnant women. ${ }^{7}$ In 1994, in the Nord Pas de Calais region, where intoxication is frequent, it was observed that $5.4 \%$ of the victims were pregnant women. ${ }^{8}$ In USA, the frequency was as high as $8.5 \%{ }^{9}$

Inhalation of $\mathrm{CO}$ ends in tissue hypoxia by inhibiting transport, delivery and utilisation of oxygen. It interferes with cellular metabolism not only by binding to haemoglobin and myoglobin but also by the inhibition of cytochrome $\mathrm{a}_{3}$ and cytochrome P-450. Recent studies suggest other mechanisms of $\mathrm{CO}$ mediated toxicity. Hypoxia may be followed by reoxygenation and reperfusion injury. ${ }^{10} \mathrm{CO}$ exposure has been shown to cause lipid peroxidation, ${ }^{11}$ and the production of free oxygen radicals. ${ }^{12} \mathrm{CO}$ toxicity is not only mediated by hypoxia but also by reperfusion injury.

CO passes through the placenta either by passive diffusion, ${ }^{13}$ or by the facilitated mechanism of a carrier. ${ }^{14}$ Placental CO diffusion capacity increases with gestational age and in proportion to fetal weight. ${ }^{15}$ This is attributable to the rate of placental blood flow and maternal haemoglobin concentration. ${ }^{16}$ The increased area of placental exchange and the decreased distance between maternal and fetal blood are probably partially responsible for this change. Slow dissociation of $\mathrm{CO}$ from maternal haemoglobin accounts for the delay in the release of $\mathrm{CO}$ and for the accumulation of $\mathrm{CO}$ in the fetus. ${ }^{17}$ Acute $\mathrm{CO}$ toxicity in pregnancy causes fetal tissue hypoxia through two mechanisms: decreased levels of release of maternal oxygen and the transplacental passage of CO. As maternal carboxyhaemoglobin rises and the blood oxygen content decreases, oxygen release by haemoglobin is diminished, and oxygen transport across the placenta decreases dramatically. ${ }^{16}$ The fetal umbilical vein oxygen decreases and tissue hypoxia occurs. ${ }^{18}$ The fetus is unable to increase cardiac output to compensate this decrease in oxygen. ${ }^{19}$ The CO has not yet crossed the placenta yet the fetus already suffers from hypoxia. Maternal carboxyhaemoglobin dissociation creates a pressure gradient between maternal and fetal blood. CO crosses the placenta and combines with fetal haemoglobin. Fetal carboxyhaemoglobin levels are approximately $10 \%-15 \%$ higher than maternal levels. ${ }^{19}$ Elimination is slower in the fetus. ${ }^{18}{ }^{20}$ Maximal concentrations of $\mathrm{CO}$ in fetal blood are found after about four hours. ${ }^{19}$

Hyperbaric oxygen not only accelerates the dissociation of $\mathrm{CO}$ from haemoglobin and from the mitochondrial respiratory chain but also increases the level of dissolved oxygen in
Accepted for publication 26 September 2000 
Table 1 Clinical grading of central nervous system severity for acute carbon monoxide poisoning victims ${ }^{30}$

\begin{tabular}{ll}
\hline Grade & Symptoms \\
\hline Grade 1 & $\begin{array}{l}\text { oriented for time, place and person } \\
\text { headache, dizziness, nausea } \\
\text { disorientation for time, place or person } \\
\text { confusion or abnormal behaviour } \\
\text { headache, nausea, dizziness } \\
\text { disorientation, loss of recent memory, muscle weakness or incoordination } \\
\text { if intubated: appropriate responses to simple commands } \\
\text { not intubated: inappropriate responses to simple commands } \\
\text { intubated: requiring sedation } \\
\text { Grade } 4\end{array}$ \\
Grade 5 & $\begin{array}{l}\text { romatose } \\
\text { responding only to pain } \\
\text { not responding to any stimulus }\end{array}$ \\
\hline
\end{tabular}

blood and thus prevents further injury. Its action on free radical production has recently been emphasised.

Oxygen shortens the half life of carboxyhaemoglobin, which is four to five hours at atmospheric oxygen levels. Hyperbaric oxygen reduces this half life to 20 minutes. Fetal carboxyhaemoglobin half life in hyperbaric conditions is unknown. Reduction of maternal carboxyhaemoglobin probably greatly contributes to the prompt reduction in fetal levels. Approximately $98.5 \%$ of oxygen binds to haemoglobin and only $1.5 \%$ is dissolved in normobaric, normoxic conditions. Plasma volume increases by about $50 \%$ during pregnancy, theoretically permitting the dissolved oxygen levels to rise. At rest, the tissues extract 5 to $6 \mathrm{ml}$ of oxygen per decilitre. ${ }^{21} \mathrm{With}$ a $100 \%$ administered oxygen at 3 ATA, dissolved oxygen content is approximately $6 \mathrm{ml}$ per decilitre of blood, which satisfies tissue needs ${ }^{22}$ without any contribution from haemoglobin bound oxygen. Hyperbaric oxygen reduces the production of free radicals, ${ }^{23}$ whereas normobaric oxygen is unable to reduce free radical concentration. $^{24}$

The level of fetal morbidity and mortality in acute carbon monoxide poisoning is significant. The teratogenicity of CO is controversial. Norman et al, from a review of the literature, have concluded that anatomical malformations are more frequent when intoxication occurs during the first stage of gestation ${ }^{25}$ : malformations were reported in 6 of 12 cases. Skeletal abnormalities are frequent: malformations of the limbs are common. When exposure happens in the later stages of pregnancy, anatomical malformations are rare: one case of $48 .^{25}$ Courtens proposes the systematic screening for acute exposure to $\mathrm{CO}$ in early pregnancy in every reported case of malformation syndrome. ${ }^{26}$ The fetal brain seems to be more sensitive to $\mathrm{CO}$ during the late gestational stage. ${ }^{27}$ However, at any stage of pregnancy, functional changes in psychomotor and mental development can appear. The abnormalities described in the literature are similar to those observed after other types of hypoxic injury to the central nervous system in the prenatal period. Since Breslau and Freund, several reported cases of fetal death have been published. Maternal death certainly leads to fetal death. In cases of maternal coma, fetal death is probable. However, maternal wellbeing is misleadingly reassuring. Fetal death can still occur even in the presence of apparent maternal wellbeing. ${ }^{14} 151928$ The severity of damage depends on the degree and duration of hypoxia or asphyxia. Death or permanent neurological damage can follow a single episode of hypoxia.

Fetal prognosis is difficult to estimate. The level of carboxyhaemoglobin has been proposed as a criterion but maternal symptoms seem to be the best indicators of fetal prognosis. The carboxyhaemoglobin level is only valuable in the confirmation of exposure to $\mathrm{CO}$ and has little correlation with the gravity of the outcome. Maternal carboxyhaemoglobin levels do not accurately reflect fetal haemoglobin or tissue levels. ${ }^{17}$ Kopelman et al report the case of a pregnant woman who had been exposed to exhaust fumes with a carboxyhaemoglobin level (after two hours) of $6.9 \% .{ }^{29}$ Her symptoms were headache, dyspnoea and dizziness. Six days later, at term, the infant presented signs of multiorgan injury resulting from in utero hypoxia. The fetus had been more severely affected than the mother. According to Norman et al, the maternal symptoms predict the wellbeing of the fetus. ${ }^{25}$ When the mother suffers a period of unconsciousness or coma, the fetal outcome is poor, but when the severity of maternal toxicity is graded as mild the fetal outcome is generally good. On the other hand, if the mother dies, fetal death inevitably follows. Koren et al, using a classification by grades (table 1), observe that grades 1-2 have a good fetal outcome. ${ }^{30}$ Grades 4-5 have a seriously adverse outcome and according to this author termination of pregnancy should be envisaged in these cases.

The treatment of acute CO poisoning during pregnancy begins by removing the victim from the environmental source of CO. Then 100\% normobaric oxygen should be administered immediately and hyperbaric oxygen should be considered. The safety of hyperbaric oxygen administration for the fetus is still to be established. Some published studies suggest that hyperbaric oxygen administration entails a risk of abortion and fetal defects. ${ }^{31}{ }^{32}$ In animal studies hyperbaric oxygen administration may be responsible for fetal reabsorption, abortion and teratogenesis. Prolonged administration of hyperbaric oxygen, as used in non-human studies, is clearly teratogenic. ${ }^{33}$ However, Elkharrat et al maintain there is no evidence of fetal or obstetric morbidity if the following protocol is observed: a two hour session of hyperbaric oxygen administered at 2 ATA. $^{7}$ In Koren's study, two cases of grade 4-5 intoxication resulted in a normal outcome after treatment with hyperbaric oxygen. Sporadic cases reveal no adverse effects on the fetus after hyperbaric oxygen administration. ${ }^{32} 3435$

It is admitted that fetal malformation and hypotrophy risks are, after hyperbaric oxygen, as significant as that of the general population. ${ }^{7}$ It has been suggested that exposure to hyperbaric oxygen during the first stage of pregnancy can induce abortion or premature labour. ${ }^{32}$ The only reported case of premature labour related to hyperbaric oxygen administration was probably fortuitous according to the authors. ${ }^{32}$ 


\section{Conclusion}

Acute $\mathrm{CO}$ poisoning during pregnancy is comparatively uncommon, yet can result in fetal death and functional alterations or anatomical malformations in survivors. The level of maternal CO haemoglobin is a poor indicator of fetal toxicity. Despite maternal wellbeing, fetal morbidity or mortality can still occur. Hyperbaric oxygen seems to be the treatment of choice and all pregnant women suffering $\mathrm{CO}$ intoxication should be referred for hyperbaric oxygen therapy. It should be instituted as rapidly as possible, yet its efficacy is still theoretically possible long after initial exposure. In human protocol, the hyperoxic period is short and well tolerated by the fetus.

Funding: none.

Conflicts of interest: none.

Contributors

$\mathrm{J} L \mathrm{Greingor}$ is guarantor of the paper.

1 Office for National Statistics. Mortality statistics cause: England and Wales. London: HMSO, 1996. Series DH2 No23.

2 Conseil Superieur d'Hygiene Publique de France. Depistage systematique de l'intoxication par le monoxyde de carbone [Systematical detection of carbon monoxide intoxication] [In French]. Revue du SAMU 1994;3:125.

3 Cobb N, Etzel RA. Unintentionnal carbon monoxiderelated deaths in the United States, 1979 through 1988. related deaths in the United 1991;266:659-63.

4 Hardy KR, Thom SR. Pathophysiology and treatment of carbon monoxide poisoning. F Toxicol Clin Toxicol 1994;32: carbon $\mathrm{m}$.

5 Breslau F. Intoxication zweir Schwangeren mit Halzleuchtgas Tod und vorzeitige Geburt eines Kindes. Mschr Geburt Frauenkr 1859;13:449-56.

6 Freund MB. Accidental death of the 7 month foetus as a result of slight intoxication of the mother with carbon monoxide gas. Mschr Geburt Frauenkr 1859;14:31-3.

7 Elkharrat D, Raphael JC, Korach JM, et al. Acute carbon monoxide intoxication and hyperbaric oxygen in preg-
nancy. Intens Care Med 1991;17:289-92.

8 Wattel F, Mathieu D, Neviere R, et al. L'intoxication au monoxyde de carbone [Carbon monoxide poisoning] [In French]. Presse Med 1996;25:1425-9.

9 Hyperbaric Center Advisory Committee Emergency Medical Service, City of New York. A registry for carbon monoxide poisoning in New York city. $\mathcal{F}$ Toxicol Clin Toxicol oxide poisoning

10 Zhang J, Piantadosi CA. Mitochondrial oxidative stress after carbon monoxide hypoxia in the rat brain. $\mathcal{F}$ Clin Invest 1992;90:1193-9.

11 Thom SR. Deshydrogenase conversion to oxidase and lipid peroxidation in brain after carbon monoxide poisoning. $f$ Appl Physiol 1992;73:1584-9.

12 Thom SR. Carbon monoxide mediated brain lipid peroxidation in the rat. F Appl Physiol 1990;68:997-1003.

13 Ginsberg MD, Myers RE. Fetal brain damage following maternal carbon monoxide intoxication: an experimental study. Acta Obstet Gynecol Scand 1974;53:309-17.

14 Caravati EM, Adams CJ, Joyce SM, et al. Fetal toxicity associated with maternal carbon monoxide poisoning. Ann Emerg Med 1988;17:714-17.
15 Cramer CR. Fetal death due to accidental maternal carbon monoxide poisoning. F Toxicol Clin Toxicol 1982;19:297301 .

16 Christensen P, Gronlund J, Carter AM. Placental gas exchange in the guinea pig: fetal blood gas tensions following the maternal oxygen capacity with carbon monoxide. $\mathcal{F}$ Dev Physiol 1986;8:1-9.

17 Curtis GW, Algeri EJ, McBay AJ, et al. The transplacental diffusion of carbon monoxide. Arch Pathol Lab Med 1955;59:677-90.

18 Margulies JL. Acute carbon monoxide poisoning during pregnancy. Am f Emerg Med 1986;4:516-19.

19 Longo LD. The biological effects of carbon monoxide on the pregnant woman, fetus and newborn infant. $\mathrm{Am} f$ Obstet Gynecol 1977;129:69-103.

20 Hill EP, Hill JR, Power GG, et al. Carbon monoxide exchanges between the human fetus and mother: a mathematical model. Am f Physiol 1977;232:H311-23.

21 Kety SS, Schmidt CF. The effects of altered arterial tensions of carbon dioxide and oxygen cerebral blood flow and cerebral oxygen consumption of normal young men. 7 Clin Invest 1948;27:484-92.

22 Lambertsen CJ, Kough RH, Cooper DY, et al. Oxygen toxicity : effects in man of oxygen inhalation at 1 and 3.5 atmospheres upon blood gas transport, cerebral circulation and cerebral metabolism. F Appl Physiol 1953;5:471-86.

23 Thom SR. Antagonism of carbon monoxide-mediated brain lipid peroxidation by hyperbaric oxygen. Toxicol Appl Pharmacol 1990;105:340-4.

24 Brown S, Piantadosi C. Recovery of energy metabolism in the rat brain after carbon monoxide poisoning. 7 Clin Invest 1992;89:666-72.

25 Norman CA, Halton DM. Is carbon monoxide a workplace teratogen ? A review and evaluation of the litterature. Ann Occup Hyg 1990;4:335-47.

26 Courtens W, Hennequin Y, Blum D, et al. Charge association in a neonate exposed in utero to carbon monoxide. Birth Defects 1996;1:407-12.

27 Okeda R, Matsuo T, Kuroiwa T, et al. Experimental study on pathogenesis of the fetal brain damage by acute carbon monoxide intoxication of the pregnant mother. Acta Neuropathol 1986;69:244-52.

28 Muller GL, Graham S. Intrauterine death of the foetus due to accidental carbon monoxide poisoning. $N$ Engl $\mathcal{F} \mathrm{Med}$ $1955 ; 25: 1075-8$.

29 Kopelman AE, Plaut TA. Fetal compromise caused by maternal carbon monoxide poisoning. F Perinatol 1998;18: $74-7$.

30 Koren G, Sharav T, Pastuszak A, et al. A multicenter prospective study of fetal outcome following accidental carbon monoxide poisoning in pregnancy. Reprod Toxicol 1991;5:397-403.

31 Grote W, Wagner WD. Malfomations in rabbit embryos after hyperbaric oxygenation. Klin Wochenschr 1973;51: $248-50$.

32 Hollander D1, Nagey DA, Welch R, et al. Hyperbaric oxygen therapy for the treatment of acute carbon monoxide poisoning in pregnancy. A case report. F Reprod Med 1987; 32:615-17.

33 Miller PD, Telford IR, Haas GR. Effect of hyperbaric oxygen on cardiogenesis in the rat. Biol Neonate 1971;17: $44-52$.

34 Van Hoessen KB, Camporesi EM, Moon RE, et al. Should hyperbaric oxygen be used to treat the pregnant patient for acute carbon monoxide poisoning ? A case report and literature review. fAMA 1989;7:1039-43.

35 Ledingham IM, McBride TI, Jennett WB, et al. Fatal brain damage associated with cardiomyopathy of pregnancy with notes on caeserean section in a hyperbaric chamber. BMF $1968 ; 4: 285-7$ 